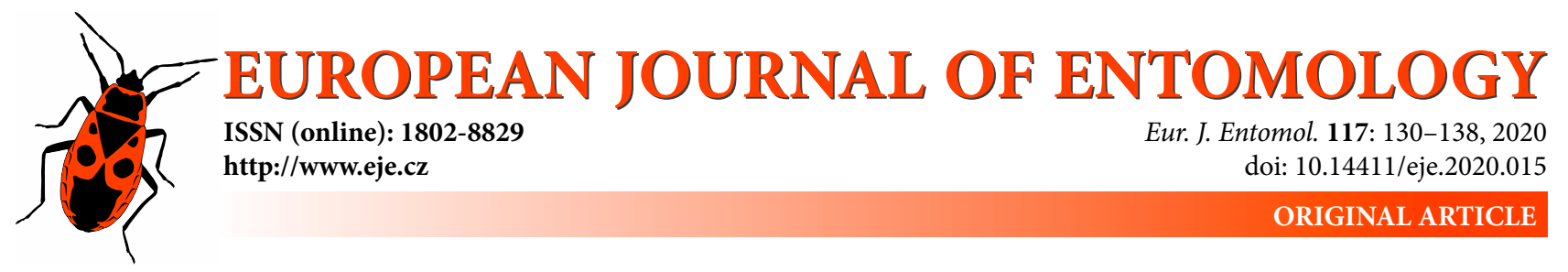

\title{
Forecasting the spread associated with climate change in Eastern Europe of the invasive Asiatic flea beetle, Luperomorpha xanthodera (Coleoptera: Chrysomelidae)
}

\author{
Mattia IANNElla, Paola D’AlessandRo and Maurizıo BIONDI \\ Department of Life, Health and Environmental Sciences, University of L'Aquila, 1 Piazzale Salvatore Tommasi, Blocco 11, \\ L’Aquila 67100, Italy; e-mails: mattia.iannella@univaq.it, paola.dalessandro@univaq.it, maurizio.biondi@univaq.it
}

Key words. Chrysomelidae, Galerucinae, Alticini, Luperomorpha xanthodera, global warming, biological invasions, Ecological Niche Modelling, Europe

\begin{abstract}
The current climate has facilitated biological invasions worldwide, with the spread of invasive species accelerating over the last few decades. Introductions of species are often accidental and facilitated by many factors, including intercontinental trade. In this paper, we explore the secondary range of an adventive flea beetle native to Asia, Luperomorpha xanthodera, which was recently found in many European countries on several occurrences. This species has detrimental effects mainly on ornamental plants, being destructive to leaves and flowers, which can have serious negative economic consequences. We inferred current and future potential distribution of this alien species using Ecological Niche Modelling (ENM) and analysed the future increase in suitable areas in European countries. Suitable climatic conditions for L. xanthodera are assumed to be similar to that in areas where this species currently occurs, which includes Ireland and some Balkan countries, where the species is not recorded yet. In the future, a North-eastern expansion is predicted, with many countries currently lacking suitable climatic conditions for $L$. xanthodera becoming suitable and potentially colonizable by this species. The geographic trend revealed and quantified in our analysis follows the increase in the mean temperature in the coldest quarter of the year, which is predicted to rise in the next 30 years. This will result in this species spreading from south-western Europe to North-Eastern countries, such as Poland, Ukraine, Romania, Belarus and Latvia, which should adopt preventive measures to avoid the accidental introduction of $L$. xanthodera.
\end{abstract}

\section{INTRODUCTION}

The ongoing climate change is one of the most important phenomena shaping the current distribution of species, of both conservation and invasive concern (Bellard et al., 2012; Cerasoli et al., 2019; Wieczynski et al., 2019). The spread of invasive species of all taxa has increased during the last few decades (Seebens et al., 2017). Although preventive measures were adopted in both high- and low-income countries, such controls on trade in pets, stowaways in international trade and marine ports in most of them are not able to limit the increase in the number of possible unwanted introductions (Early et al., 2016). Alien species can negatively affect both biodiversity and agriculture, which generate expensive management issues (Allison et al., 2009; Paini et al., 2016; Gilioli et al., 2017).

The recent introduction of Ecological Niche Models (ENMs) for use in biodiversity conservation (Nekaris et al., 2015; Ferrer-Sánchez \& Rodríguez-Estrella, 2016; Iannella et al., 2018), biogeographical analyses (Pelletier \& Carstens, 2016; Salvi et al., 2016; D’Alessandro et al., 2018; Brunetti et al., 2019) and spread of invasive species (Gallien et al., 2012; Barbet-Massin et al., 2018) has at- tracted attention because of its theoretical and practical applications, especially when coupled with GIS analyses (Cerasoli et al., 2017; Iannella et al., 2018).

Luperomorpha xanthodera (Fairmaire, 1888) (Coleoptera: Chrysomelidae: Galerucinae: Alticini) is an Asian polyphagous flea beetle, introduced into Europe in 2003 (Johnson \& Booth, 2004), the adults of which feed on flowers and larvae develop on the roots of many plants (23 genera from 19 families) (Del Bene \& Conti, 2009). Numerous holes chewed by these beetles in petals and the destruction of the reproductive organs of flowers may cause sterilization and deterioration in the aesthetic value of plants. L. xanthodera is easily and unintentionally introduced as larvae on roots of imported seedlings or as adults transported mainly as stowaways in the cargo in airplanes (Bieńkowski \& Orlova-Bienkowskaja, 2018b) and then spreads like many other invasive species (Early et al., 2016). In fact, the trade in imported plants can accelerate the spread of this flea beetle, especially that in ornamental plants (Johnson \& Booth, 2004; Beenen \& Roques, 2010); currently, L. xanthodera appears to be established in many areas in its secondary range (Europe). 
Considering the high number of localities at which $L$. xanthodera is recorded in Europe (first year of record: 2003, Great Britain; 2005, France; 2006, Italy; 2007, Germany; 2008, Netherlands; 2009, Montenegro; 2010, Hungary; 2011, Austria; 2012, Poland; 2014, Belgium; 2016, Spain and Russia) (Radonjić \& Hrnčić, 2017; Bieńkowski \& Orlova-Bienkowskaja, 2018a) an assessment of the current and future potential spread of $L$. xanthodera in response to climate change is important for the biological and economic issues, which this alien species may bring.

In this paper, we infer potential future distribution of $L$. xanthodera in terms of gains and losses associated with the predicted changes in the geographical trends in the emissions of different greenhouse gases (GHGs). Further, the results are mainly for the countries within the species' secondary range and will help in the development of national management strategies where this species currently occurs and is predicted to occur in the future.

\section{MATERIALS AND METHODS}

\section{Species studied}

Chrysomelidae is one of the largest Coleopteran families, including over 37,000 species worldwide (Jolivet \& Verma, 2002).
This group of phytophagous beetles includes very harmful invasive taxa, which can have serious effect on the production of vegetables and fruit, and ornamental plants (Beenen \& Roques, 2010).

Luperomorpha xanthodera is of Asian origin and an adventive species in Europe since 2003 (Johnson \& Booth, 2004; Bieńkowski \& Orlova-Bienkowskaja, 2018b). Its area of origin (primary range) includes China and the Korean Peninsula [even though this last is doubtful according to Löbl \& Smetana (2010)], while the secondary range currently includes Great Britain, Spain, France, Italy, Germany, The Netherlands, Hungary, Austria, European Russia (Bieńkowski \& Orlova-Bienkowskaja, 2018a, b) and Montenegro, even though for this country the establishment of this species is doubtful (Radonjić \& Hrnčić, 2017) (Fig. 1A). This flea beetle has the potential for becoming locally abundant and destroying ornamental plants, especially the flowers (Kozłowski \& Legutowska, 2014). In Central Italy (Tuscany) it produces two, partially overlapping generations and overwinters in all post-embryonic stages (Del Bene \& Conti, 2009). Adults appear in spring and are present on plants throughout the whole vegetative season. Larval development takes place in the soil and the damage they do the roots does not seem to affect infested plants (Kozłowski \& Legutowska, 2014). More distinct damage is caused by adults that feed on plants, especially the flowers and leaves of seedlings (Del Bene \& Conti, 2009).
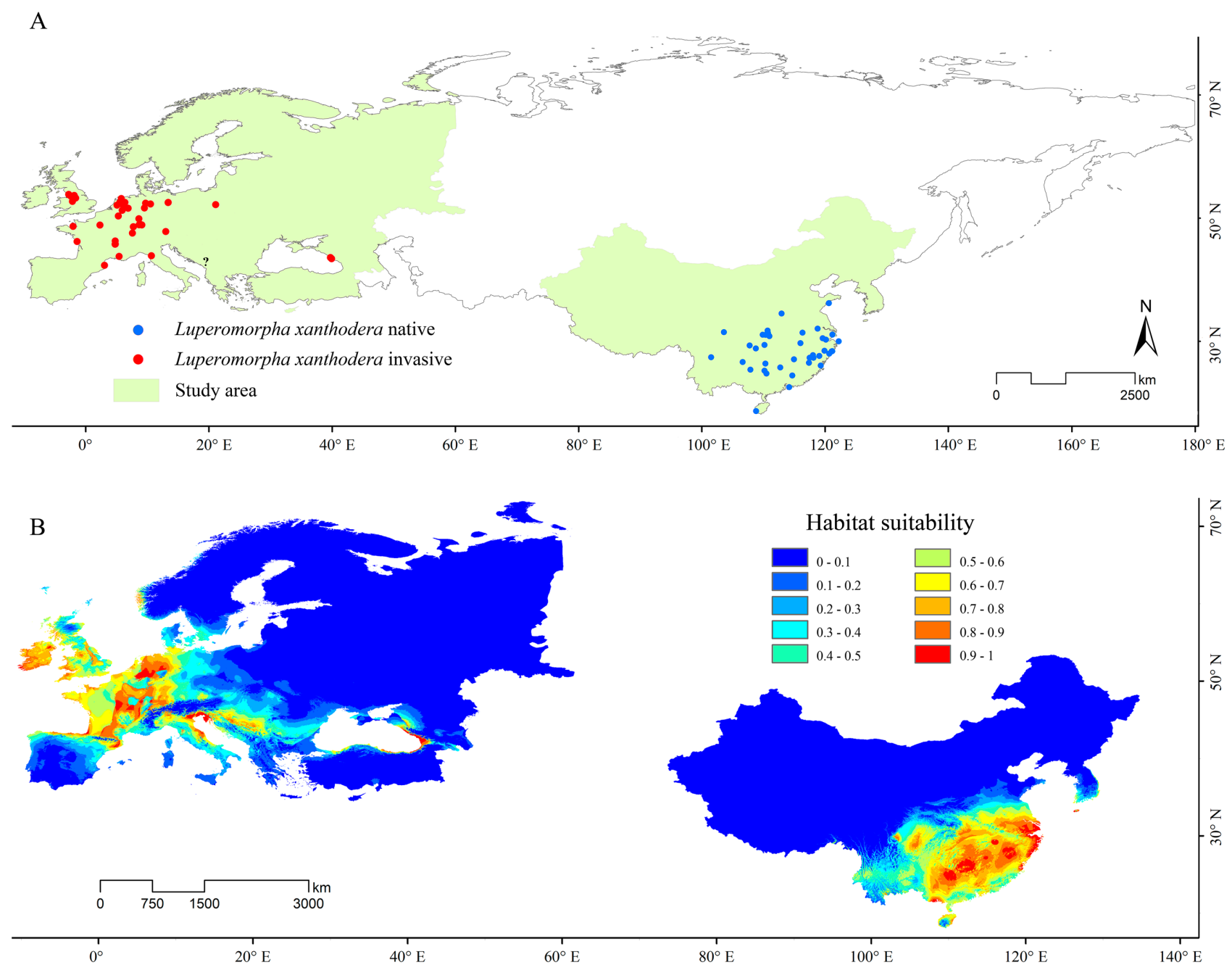

Fig. 1. A - localities where Luperomorpha xanthodera occurred in its primary (blue) and secondary (red) ranges; the question mark indicates the doubtful occurrence in Montenegro. B - predicted habitat suitability for $L$. xanthodera under current climatic conditions ranging from low $(0-$ blue $)$ to high $(1-$ red $)$. 

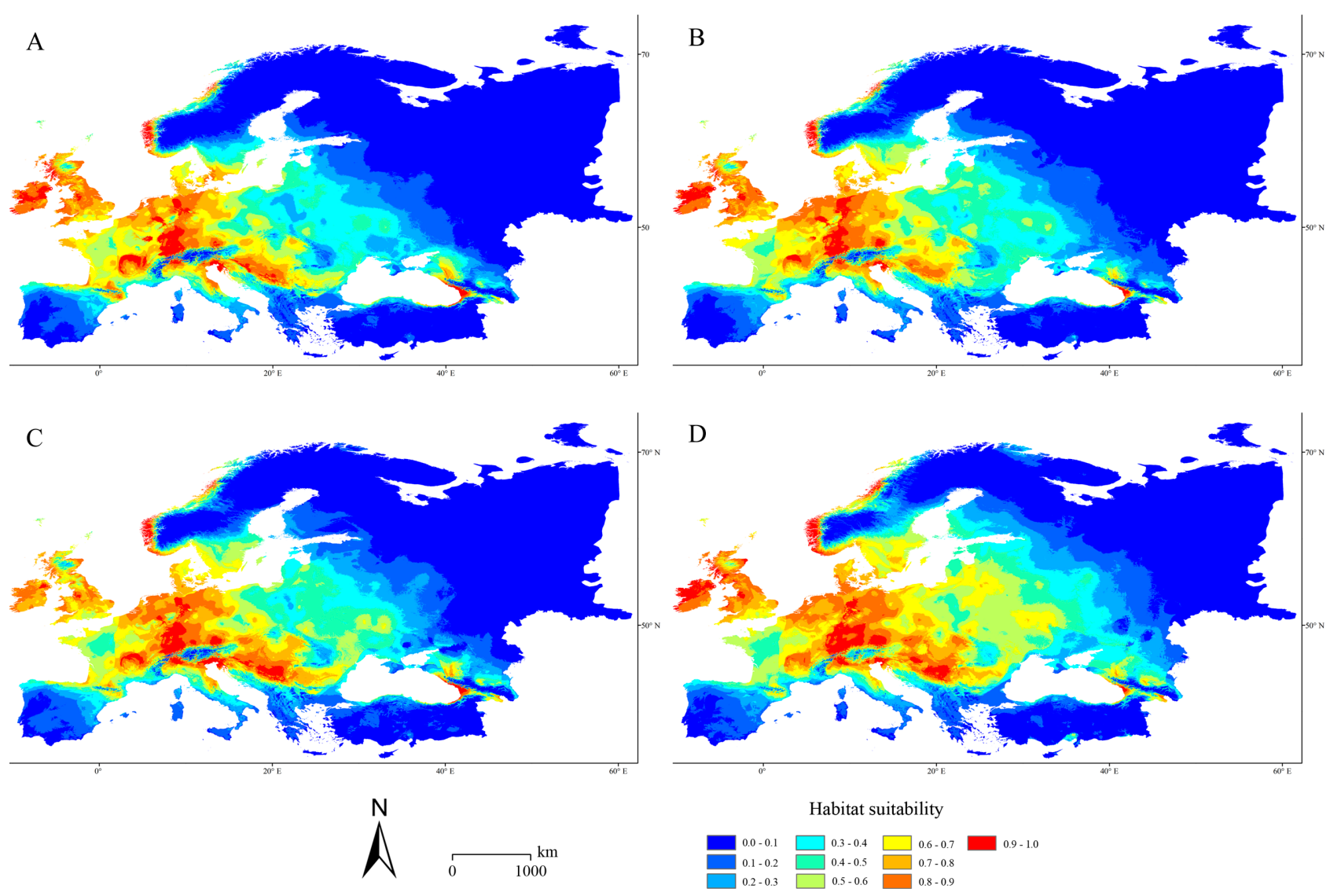

Fig. 2. Model predictions of habitat suitability of Luperomorpha xanthodera in its secondary range for different future climatic conditions. A - 2050 RCP_6.0, B - 2050 RCP_8.5, C - 2070 RCP_6.0, D - 2070 RCP_8.5.

\section{Dataset and study area}

The localities where L. xanthodera occurs were obtained from the two most recent papers on this species in both its primary (Wang et al., 2010) and secondary (Bieńkowski \& Orlova-Bienkowskaja, 2018a) ranges, along with some new data from Italy (Lombardia and Veneto, M. Biondi, unpubl.). These papers were chosen because they are the most recent and comprehensive studies on this species. The dataset includes 39 localities for the primary and 46 for the secondary ranges, respectively, of this species (Fig. 1A).

The whole dataset is available in Table S1, including coordinates (in WGS84) and indication of their occurrence in either the primary or secondary ranges.

\section{Ecological niche modelling}

Recently Ecological Niche Models have become more popular among ecologists for predicting the potential distribution in space and time of a species, and identifying the environmental variables associated with the distribution of taxa, even using the presence-only data reported in bibliographic sources, online databases and museum records (e.g. Ferrer-Sánchez \& RodríguezEstrella, 2016; D’Alessandro et al., 2018; Brunetti et al., 2019). Included in the Ecological Niche Models is a set of nineteen bioclimatic variables, which were downloaded from the online repository Worldclim.org, at a resolution of 30 arc-seconds, for the 'current' climatic conditions (ver. 1.4) (Hijmans et al., 2005); names and codes for each variable are in Table S2. For predicting this species' future distributions, three different sets of bioclimatic variables for future climatic conditions (2050 and 2070) were also downloaded, in order to address differences among Global Climate Models (GCMs, models represent the interac- tions among the different climatic factors) by combining them to produce each future scenario (see the use of MEDI algorithm, at the end of the current paragraph). The CCSM4 (Gent et al., 2011), IPSL (Marti et al., 2010) and MIROC-CHEM (Watanabe et al., 2011) were the GCMs chosen for this analysis (Brunetti et al., 2019; Iannella et al., 2019a). For both 2050 and 2070, the Representative Concentration Pathways (RCPs, represent the trajectories climate will take due to radiative forcing) 6.0 and 8.5 were used to model this species' response to different scenarios of greenhouse gas (GHGs) emissions. The RCP_6.0 is the result of the increased radiative forcing due to GHGs emissions decreasing only after 2080 , while RCP 8.5 considers the emissions continuing to at least 2100 (Meinshausen et al., 2011; Riahi et al., 2011), thus, considering both a "plausible" and an "extreme" climatic scenario.

To avoid multicollinearity among predictors, a correlation matrix was built from which pairs of variables exceeding Pearson's $|r|>0.85$ were removed (Elith et al., 2006). In addition, the occurrences database (both for primary and secondary ranges) was also checked for correlation among records using the Moran test in ArcMap 10.0 (ESRI, 2010).

Models were built using the Maxent algorithm implemented in the SDMtoolbox ver. 2.4 (Brown et al., 2017) in ArcMap 10.0; this tool permits the use of the high performance Maxent algorithm (Elith et al., 2006; Wisz et al., 2008) coupled with spatial jack-knifing, a procedure which geographically performs the cross-validation (Brown, 2014) used to model several conservation and biogeographical issues (Kumar et al., 2015; Iannella et al., 2018b; Hill \& Winder, 2019). A sampling bias mask was generated using the 'Gaussian kernel density of sampling localities' (sampling bias distance $=50 \mathrm{~km}$ ) in order to avoid the more sam- 

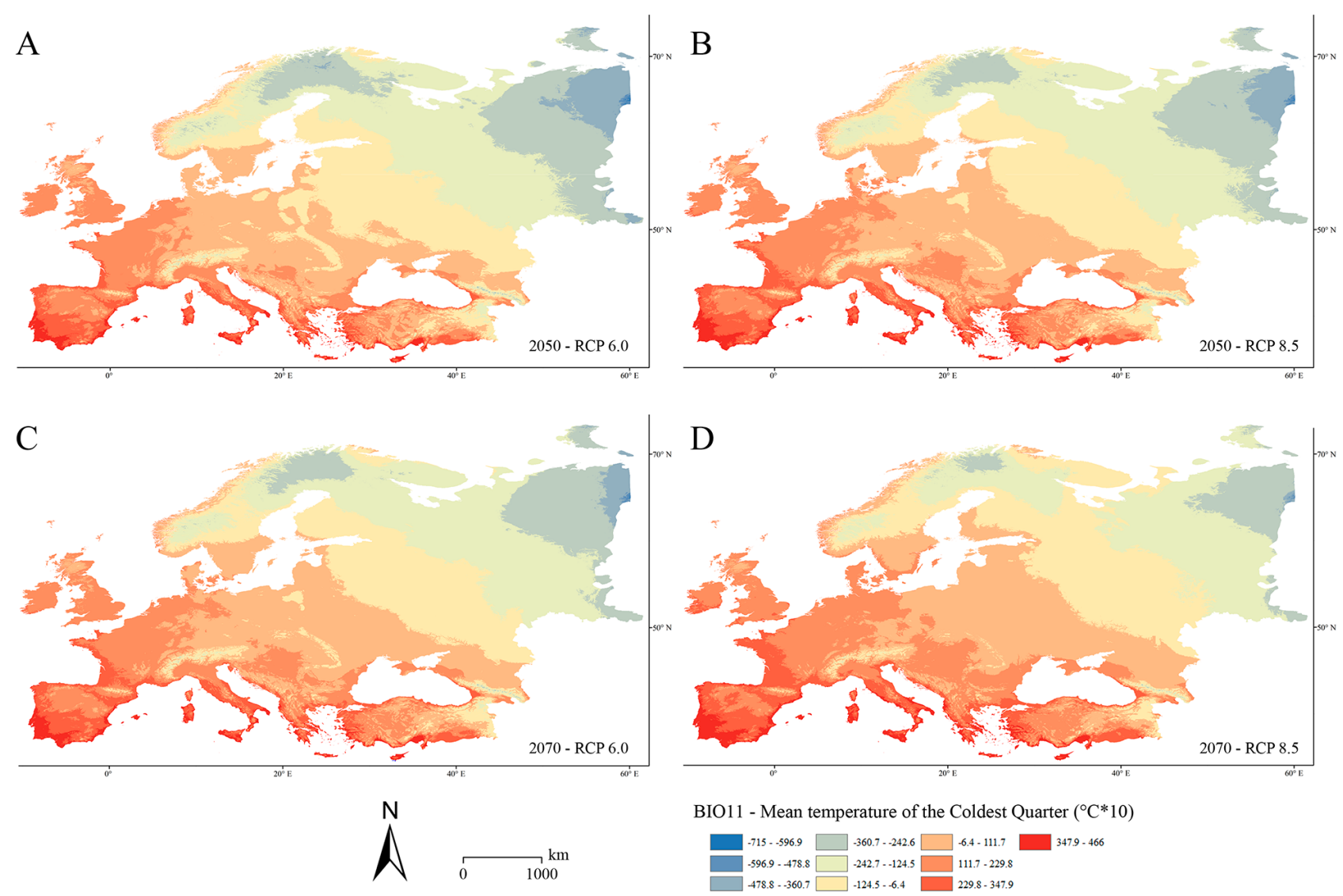

Fig. 3. Worldclim model predictions of mean temperature in the coldest quarter (BIO11) in the secondary range of $L$. xanthodera for different future climatic conditions. A - 2050 RCP_6.0, B - 2050 RCP_8.5, C - 2070 RCP_6.0, D - 2070 RCP_8.5.

pled areas having a negative effect on the models (Phillips et al., 2009). Further, all predictors were projected into an Equal Area Projection (WGS84 - Cylindrical Equal Area), to correct for any latitudinal bias (Brown, 2014); spatial jack-knife was set at 5 replicates per parameter and 3 spatial groups were created. Models were calibrated for both primary and secondary range localities of this species, a technique used to improve performance of predictions and reduce uncertainties (Broennimann \& Guisan, 2008) when modelling the distribution of invasive species (Cerasoli et al., 2019; Iannella et al., 2019a; Perret et al., 2019; RodríguezRey et al., 2019).

The occurrences of spatial autocorrelations were tested for using the Moran test in ArcMap 10.0 ['Spatial Autocorrelation (Global Moran's I)' toolbox]; this test identifies patterns of regular occurrence, clustering or spatial independence of the localities where this species is present (ESRI, 2010).

This workflow was used to both lower geographic and possible self-correlation biases in the occurrence data and facilitate tests of the different types of features and regularization of multipliers, resulting in higher model performances (Brown et al., 2017).

For each model based on the different GCMs used, the Area Under the Curve (AUC) of the Receiver Characteristics Operator (ROC) was used as a weight in the Multivariate Environmental Dissimilarity Index (MEDI) algorithm (Iannella et al., 2017), which proportionally combines different GCMs projections, starting with the MESS (Elith et al., 2010) maps produced by Maxent, which down-weights the extrapolations of the models. Both current and future predicted scenarios were binarized using the $10^{\text {th }}$ percentile of training presences, which is a reliable and conservative threshold when data are collected at different times by several observers (Freeman \& Moisen, 2008; Rebelo \& Jones, 2010; Urbani et al., 2015, 2017).

\section{Post-modelling analyses}

To determine possible changes in range, current and future binarized maps were compared using the 'BIOMOD_RangeSize' function in the 'biomod2' package (Thuiller et al., 2016) in R (R Core Team, 2016); this function calculates loss, similarity and gain of area when comparing two binarized maps, for instance a current and a future map, as in our case. Gains were analysed using ArcMap 10.0 on a latitude-longitude grid (1 square degree) to measure possible shifts and areas in each cell. All geographic data and the corresponding maps were managed in ArcMap 10.0.

\section{RESULTS}

The Moran's test of the localities of the occurrences resulted in $\mathrm{I}=-0.0262$, with $\mathrm{z}$-score $=0.000880$ and $\mathrm{p}=$ 0.9992 for the primary range and $\mathrm{I}=-0.0182$, with $\mathrm{Z}$-score $=0.1112$ and $\mathrm{p}=0.9114$ for the secondary range, which indicates random distributions in both ranges. The correlation matrix of all the candidate predictors resulted in eight variables being selected for modelling, namely BIO1 (Annual Mean Temperature), BIO5 (Maximum Temperature in Warmest Month), BIO8 (Mean Temperature in Wettest Quarter), BIO10 (Mean Temperature in Warmest Quarter), BIO11 (Mean Temperature in Coldest Quarter), BIO12 (Annual Precipitation), BIO13 (Precipitation in Wettest Month) and BIO14 (Precipitation in Driest Month) (Table S2). 
A

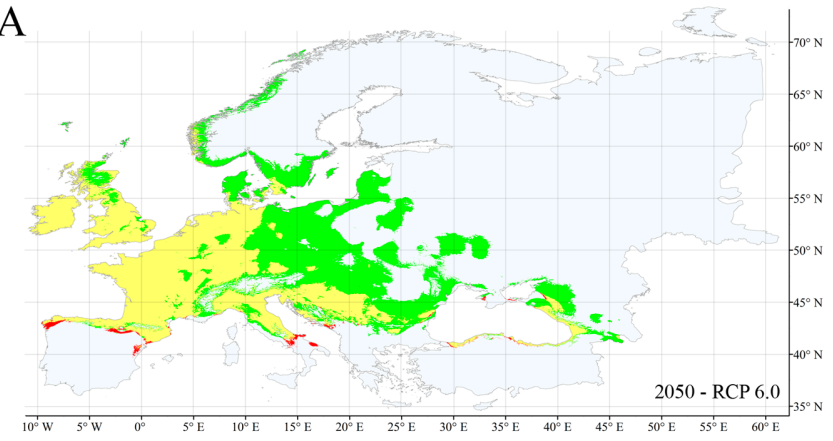

$\mathrm{B}$

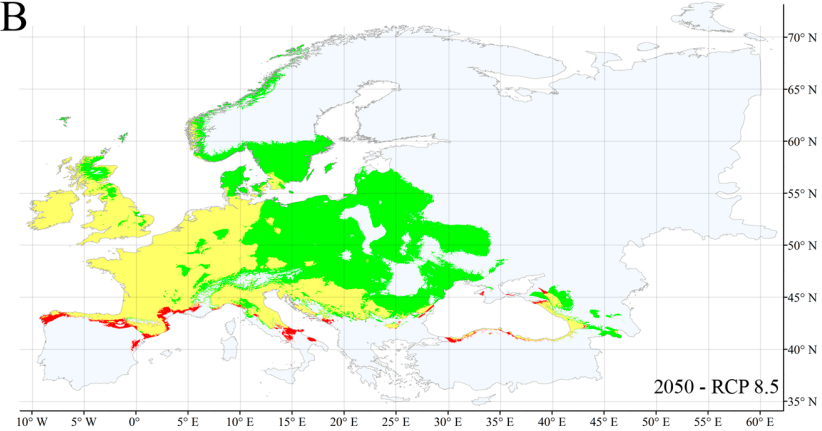

$\mathrm{C}$
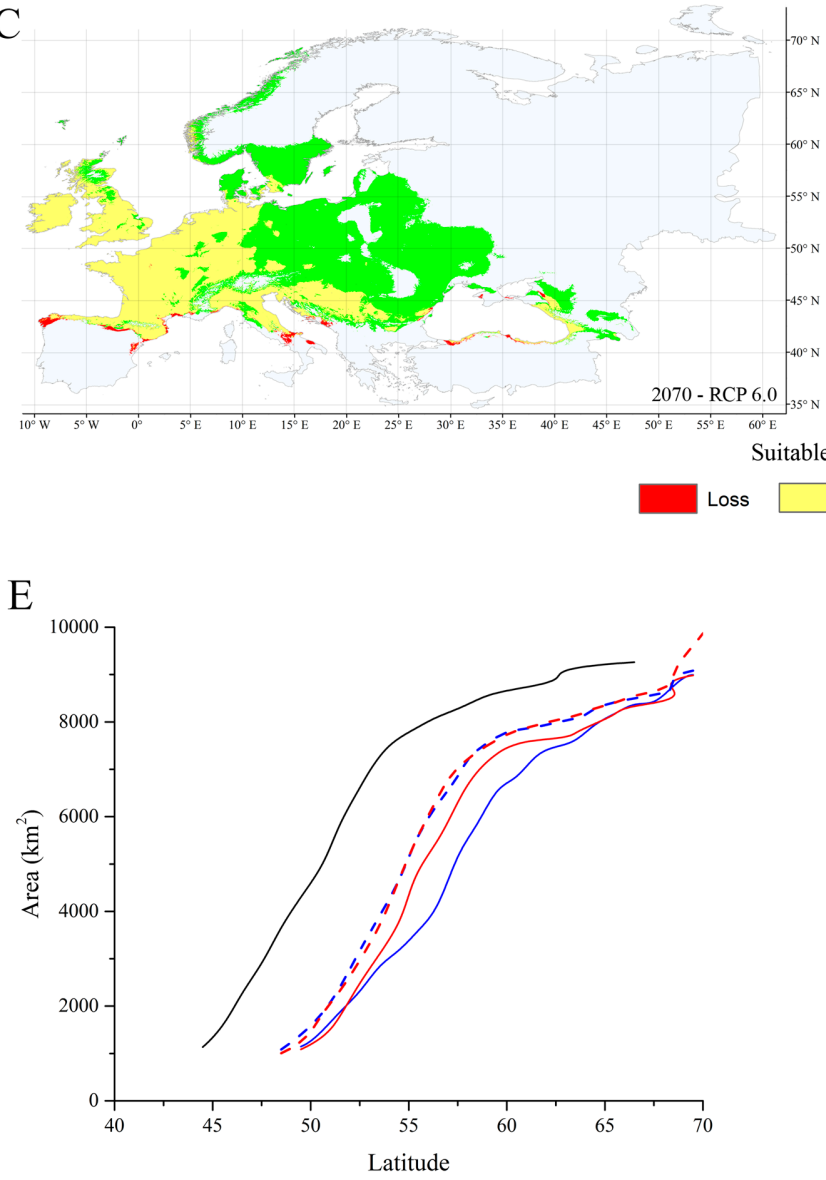

Current

(suitable)
D

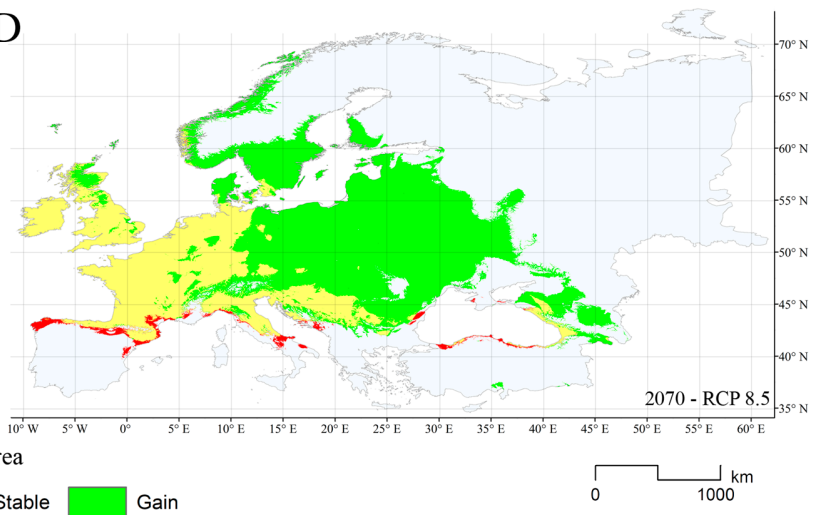

$\mathrm{F}$

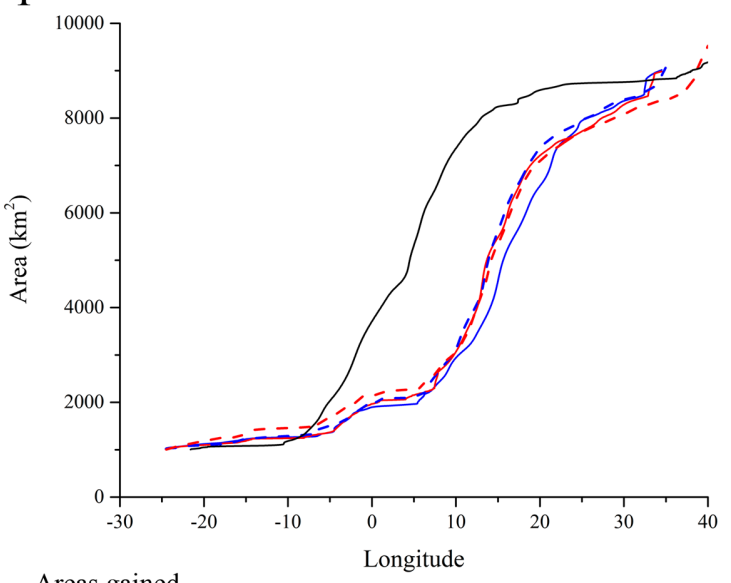

Areas gained

2050_6 - - 2070_6

2050_8 - - 2070_8

Fig. 4. Shifts in the in the secondary range of $L$. xanthodera predicted for the different future climatic conditions. A - 2050 RCP_6.0, B 2050 RCP_8.5, C-2070 RCP_6.0, D - 2070 RCP_8.5; latitudinal $(E)$ and longitudinal $(F)$ gain in areas under current and future predicted scenarios.

Models had high AUC values, with an average value $=$ 0.915 and standard deviation $=0.014$, which indicates that habitats mainly in Central Europe, British Isles, parts of Italy and the Balkans, and a small are in Southern Russia (Fig. 1B) are currently suitable. The most important variables are: Mean Temperature in Coldest Quarter (BIO11 $=63.4 \%)$ and Precipitation in Driest Month $(\mathrm{BIO} 14=$ $22.2 \%$ ), with the first showing a preference for mean temperatures between $5.5^{\circ}$ and $11.1^{\circ} \mathrm{C}$ during the coldest months and the second a preference for precipitation of $>$ $50 \mathrm{~mm}$ (Fig. S3).
The 10th percentile training presence calculated for each replicate resulted in an average value of 0.384 , which was used as the threshold for the binarization of current and future predictions. The future predictions (Fig. 2) show an increase in the area suitable for L. xanthodera in Central Europe and a noticeable trend in a greater suitability in Eastern European Countries and European Russia, apparently resulting from an increase in the most important variable BIO11 (Fig. 3). The trend is obvious in the range-shift maps (Fig. 4A-D), where areas gained are mainly in the aforementioned areas, especially in RCP_8.5 (Figs 4B, D). 

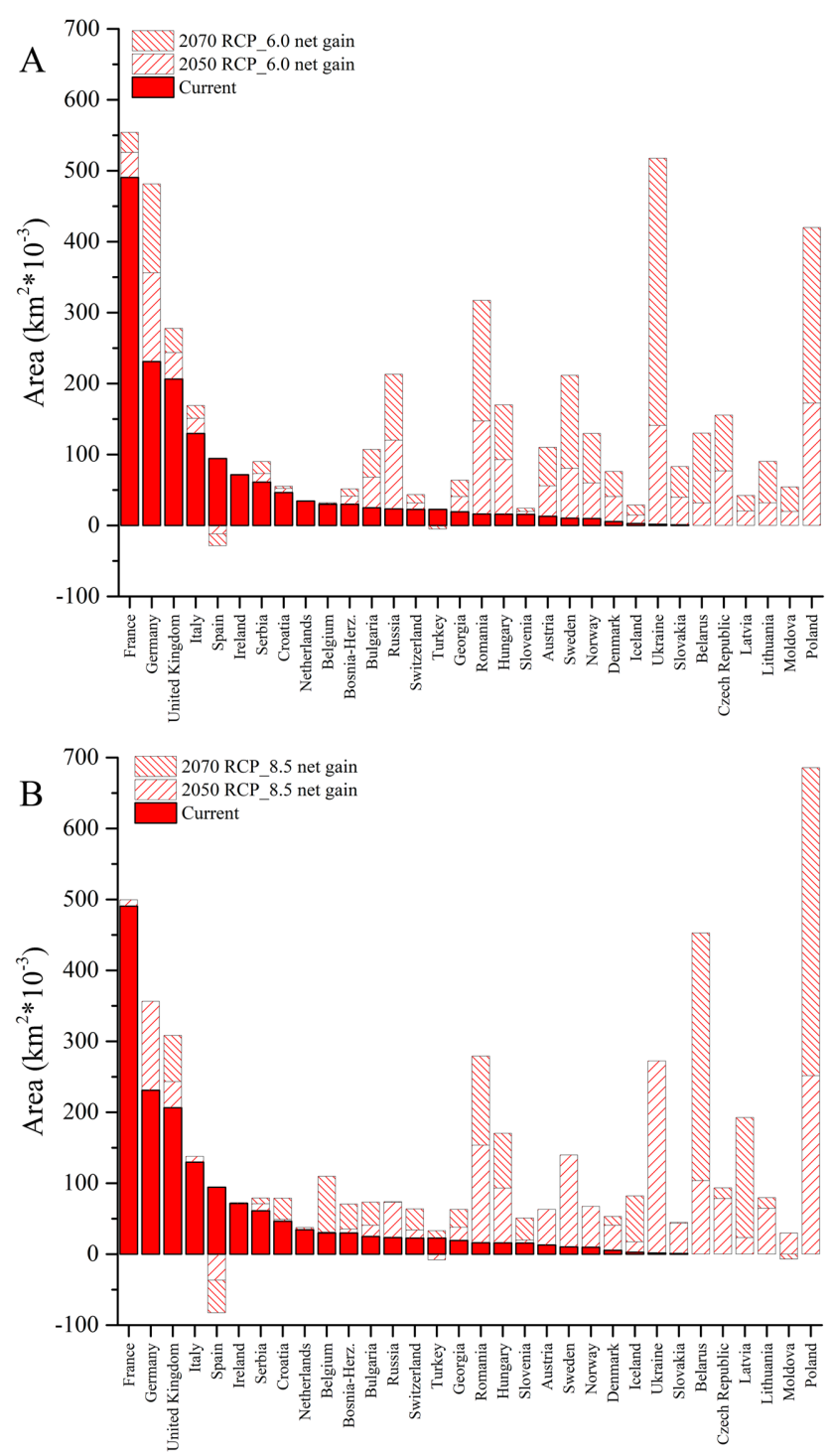

Fig. 5. Suitable areas for $L$. xanthodera under current climatic conditions in the different countries (red bars) and predicted net gains (gain - loss) for 2050 (medium density pattern) RCP_6.0 (A) and 2070 (high density pattern) RCP_8.5 (B). Countries hosting current

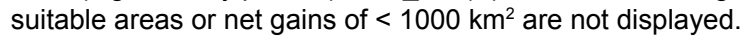

The latitude and longitude analysis using these maps further confirmed this trend (Fig. 4E, F) and shows that a parallel increase in areas gained is predicted in terms of both latitude and longitude. Considering this species' secondary range, the results also indicate a north-eastern shift in terms of countries hosting current and future suitable conditions (Fig. 4). The countries currently with highly suitable areas are mainly France, Germany, the British Isles and Italy (Fig. 5), which host $69.3 \%$ of the total binarized suitable area. The future predictions indicate that the country's most likely to be colonized by this species are the East-European ones, mainly Poland, Ukraine and Romania (Figs 5A, B), with noticeable peaks in the RCP_8.5 of Latvia and Belarus (Fig. 5B). In terms of the net gain for each country (net gain $=$ gain - loss) and corresponding total area of the secondary range colonized, Poland, Ukraine and Romania reach $32.5 \%$ in 2050 and the $41.5 \%$ in 2070 based on RCP 6.0 . By adding the RCP 8.5 peaks of Latvia and Belarus, the sum is $53.9 \%$ in 2050 and $51.5 \%$ in 2070 . Negative net gains are reported only for Spain and Turkey for both RCP_6.0 and RCP_8.5 scenarios, with the exception of a slight gain in 2070 based on RCP_8.5 (Fig. 5B).

\section{DISCUSSION}

The ENMs for current climatic conditions in the secondary range of this species reveal that currently suitable territories do not extend as far as the occurrences currently recorded, except for Ireland and some Balkan countries (Fig. 1B). On the contrary, Poland does not seem to have any suitable areas for L. xanthodera (Fig. 1B), even though Kozłowski \& Legutowska (2014) state that this species could become locally abundant. Interestingly, occurrences in the British Isles do not fully match the climatic potential of L. xanthodera, a condition recorded also for the Balkans; therefore, an accidental introduction of this species into these areas could be particularly dangerous as the climate there is suitable for the establishment of this species. Indeed, more attention should be paid to the northern Atlantic coasts of Spain and Portugal, and Italy and Balkan countries, to identify possible introductions of this species as our results indicate that it is highly likely that L. xanthodera is already in these countries. Such unrecorded occurrences limit the present study, as these could confirm (or change) the ENMs' results. This issue is common to invasive species of leaf-beetles, whose distributions are scattered at particular localities and are not recorded every year (Bieńkowski \& Orlova-Bienkowskaja, 2018a).

The mean temperature in the coldest quarter (BIO11) seems to be important in determining a species' potential distribution, based on both its high contribution in the ENMs and its similar importance in the future (Fig. 3). This result is in line with other published trends, in which low temperatures are important in determining the distribution of insects with some invasive alien insects favoured by an increase in the low temperatures that are likely to occur with global warming in the future (Orlova-Bienkowskaja \& Bienkowski, 2016; Iannella et al., 2019b). In marked contrast, high altitude and endemic species are not favoured by the predicted temperature increase (Urbani et al., 2017; Brunetti et al., 2019; Cerasoli et al., 2020). Depending on the climatic scenario and RCP used, an increase in BIO11 is observable from south-western to north-eastern Europe, which is very similar and concurrent with the future predictions (Fig. 4). L. xanthodera, which currently produces two partially overlapping generations in Italy (Del Bene \& Conti, 2009), may thus become more invasive in the future at high latitudes in Italy, where it currently overwinters. Considering the trophic preferences of this species and the plants it is found on (Del Bene \& Conti, 2009; Vincent \& Doguet, 2011), the hypothesis of an invasion of Eastern Europe's market gardens (Beenen \& Roques, 2010) is corroborated by our future projections, in which the climatic suitability clearly increases throughout this species' secondary range. 
The geographic trend in area that will become suitable in the future shows an impressive increase in Eastern Europe, with countries currently not suitable becoming highly suitable like France, Germany and U.K. Poland, Ukraine and Romania, as well as Belarus and Latvia should adopt special measures to prevent the accidental introduction of $L$. xanthodera. In fact, on average, all the future predictions (2050 and 2070) and different climatic scenario (6.0 and 8.5 RCPs) forecast a high and diffuse increase in the area suitable for this species (Figs 2, 4).

Finally, this trend is similar to other invasions (Grapputo et al., 2005; Orlova-Bienkowskaja, 2013, 2017; Ukrainsky \& Orlova-Bienkowskaja, 2014), which leads us to conclude that special attention should be given to controlling the pests on ornamental plants, especially those being traded with eastern Europe.

ACKNOWLEDGEMENTS. We thank friends and colleagues of the Forum Entomologi Italiani (www.entomologiitaliani.net/forum), who made their data available: L. Grazioli and M. Zugno. This work was supported by the A.I.M. Project-PON R \& I 2014-2020 No. 1870582.

\section{REFERENCES}

Allison E.H., Perry A.L., Badjeck M.C., Neil Adger W., Brown K., Conway D., Halls A.S., Pilling G.M., Reynolds J.D. \& ANDREW N.L. 2009: Vulnerability of national economies to the impacts of climate change on fisheries. - Fish Fish. 10: 173-196.

Barbet-Massin M., Rome Q., Villemant C. \& Courchamp F. 2018: Can species distribution models really predict the expansion of invasive species? - PLOS ONE 13: e0193085, 14 pp.

BeEnen R. \& Roques A. 2010: Leaf and seed beetles (Coleoptera, Chrysomelidae). Chapter 8.3. - BioRisk 4: 267-292.

Bellard C., Bertelsmeier C., Leadley P., Thuiller W. \& CourCHAMP F. 2012: Impacts of climate change on the future of biodiversity. - Ecol. Lett. 15: 365-377.

Bieńkowski A.O. \& Orlova-BienkowsKaja M.J. 2018a: Alien leaf beetles (Coleoptera, Chrysomelidae) of European Russia and some general tendencies of leaf beetle invasions. - PLOS ONE 13: $0203561,23 \mathrm{pp}$.

Bieńkowski A.O. \& Orlova-Bienkowskaja M.J. 2018b: Quick spread of the invasive rose flea beetle Luperomorpha xanthodera (Fairmaire, 1888) in Europe and its first record from Russia. - Spixiana 41: 99-104.

Broennimann O. \& Guisan A. 2008: Predicting current and future biological invasions: both native and invaded ranges matter. Biol. Lett. 4: 585-589.

BRown J.L. 2014: SDMtoolbox: a python-based GIS toolkit for landscape genetic, biogeographic and species distribution model analyses. - Methods Ecol. Evol. 5: 694-700.

Brown J.L., BennetT J.R. \& French C.M. 2017: SDMtoolbox 2.0: the next generation Python-based GIS toolkit for landscape genetic, biogeographic and species distribution model analyses. - PeerJ 5: e4095, 12 pp.

Brunetti M., Magoga G., Iannella M., Biondi M. \& Montagna M. 2019: Phylogeography and species distribution modelling of Cryptocephalus barii (Coleoptera: Chrysomelidae): is this alpine endemic species close to extinction? - ZooKeys $\mathbf{8 5 6}$ : $3-25$.

Cerasoli F., Iannella M., D’Alessandro P. \& Biondi M. 2017: Comparing pseudo-absences generation techniques in Boosted Regression Trees models for conservation purposes: A case study on amphibians in a protected area. - PLOS ONE 12: e0187589, 23 pp.

Cerasoli F., Iannella M. \& Biondi M. 2019: Between the hammer and the anvil: how the combined effect of global warming and the non-native common slider could threaten the European pond turtle. - Manag. Biol. Invas. 10: 428-448.

Cerasoli F., Thuiller W., Guéguen M., Renaud J., D’Alessandro P. \& Biondi M. 2020: The role of climate and biotic factors in shaping current distributions and potential future shifts of European Neocrepidodera (Coleoptera, Chrysomelidae). - Insect Conserv. Diver. 13: 47-62.

D’Alessandro P., Iannella M., Frasca R. \& Biondi M. 2018: Distribution patterns and habitat preference for the generagroup Blepharida s.l. in Sub-Saharan Africa (Coleoptera: Chrysomelidae: Galerucinae: Alticini). - Zool. Anz. 277: 23-32.

Del Bene G. \& Contr B. 2009: Notes on the biology and ethology of Luperomorpha xanthodera, a flea beetle recently introduced into Europe. - Bull. Insectol. 62: 61-68.

Early R., Bradley B.A., Dukes J.S., Lawler J.J., Olden J.D., Blumenthal D.M., Gonzalez P., Grosholz E.D., Ibañez I. \& Miller L.P. 2016: Global threats from invasive alien species in the twenty-first century and national response capacities. Nat. Commun. 7: 12485, 9 pp.

Elith J., Graham C.H., Anderson R.P., Dudík M., Ferrier S., Guisan A., Hijmans R.J., Huettmann F., Leathwick J.R., LeHMANN A. ET AL. 2006: Novel methods improve prediction of species' distributions from occurrence data. - Ecography 29: 129-151.

Elith J., Kearney M. \& Phillips S. 2010: The art of modelling range-shifting species. - Methods Ecol. Evol. 1: 330-342.

ESRI 2010: ArcMap 10.0. ESRI, Redlands, California.

Ferrer-SÁnchez Y. \& Rodríguez-Estrella R. 2016: How rare species conservation management can be strengthened with the use of ecological niche modelling: The case for endangered endemic Gundlach's Hawk and Cuban Black-Hawk. — Global Ecol. Cons. 5: 88-99.

Freeman E.A. \& Moisen G.G. 2008: A comparison of the performance of threshold criteria for binary classification in terms of predicted prevalence and kappa. - Ecol. Model. 217: 48-58.

Gallien L., Douzet R., Pratte S., Zimmermann N.E. \& Thuiller W. 2012: Invasive species distribution models - how violating the equilibrium assumption can create new insights. - Global Ecol. Biogeogr. 21: 1126-1136.

Gent P.R., Danabasoglu G., Donner L.J., Holland M.M., Hunke E.C., Jayne S.R., Lawrence D.M., Neale R.B., Rasch P.J. \& Vertenstein M. 2011: The community climate system model version 4. - J. Climate 24: 4973-4991.

Gilioli G., Schrader G., Carlsson N., Van Donk E., Van Leeuwen C.H., Martín P.R., Pasquali S., Vilà M. \& Vos S. 2017: Environmental risk assessment for invasive alien species: A case study of apple snails affecting ecosystem services in Europe. - Environ. Impact Asses. Rev. 65: 1-11.

Grapputo A., Boman S., Lindstroem L., Lyytinen A. \& Mappes J. 2005: The voyage of an invasive species across continents: genetic diversity of North American and European Colorado potato beetle populations. - Mol. Ecol. 14: 4207-4219.

Hijmans R.J., Cameron S.E., Parra J.L., Jones P.G. \& Jarvis A. 2005: Very high resolution interpolated climate surfaces for global land areas. - Int. J. Climatol. 25: 1965-1978.

HiLl S.E. \& Winder I.C. 2019: Predicting the impacts of climate change on Papio baboon biogeography: Are widespread, generalist primates 'safe'? - J. Biogeogr. 46: 1380-1405.

Iannella M., Cerasoli F. \& Biondi M. 2017: Unraveling climate influences on the distribution of the parapatric newts Lissotri- 
ton vulgaris meridionalis and L. italicus. — Front. Zool. 14: $55,14 \mathrm{pp}$.

Iannella M., Cerasoli F., D’Alessandro P., Console G. \& BionDI M. 2018: Coupling GIS spatial analysis and Ensemble Niche Modelling to investigate climate change-related threats to the Sicilian pond turtle Emys trinacris, an endangered species from the Mediterranean. — PeerJ 6: e4969, 21 pp.

Iannella M., D’Alessandro P., Longo S. \& Biondi M. 2019a: New records and potential distribution by Ecological Niche Modelling of the adventive leaf beetle Monoxia obesula Blake in the Mediterranean area (Coleoptera, Chrysomelidae, Galerucinae). - Bull. Insectol. 72: 135-142.

Iannella M., De Simone W., D’Alessandro P., Console G. \& BIONDI M. 2019b: Investigating the current and future co-occurrence of Ambrosia artemisiifolia and Ophraella communa in Europe through ecological modelling and remote sensing data analysis. - Int. J. Environ. Res. Public Health 16: 3416, 16 pp.

Johnson C. \& Bоoтн R. 2004: Luperomorpha xanthodera (Fairmaire): a new British flea beetle (Chrysomelidae) on garden centre roses. - Coleopterist 13: 81-86.

JoliVet P. \& Verma K.K. 2002: Biology of Leaf Beetles. Intercept, Andover, MA, 332 pp.

KozŁowski M.W. \& LegutowsKa H. 2014: The invasive flea beetle Luperomorpha xanthodera (Coleoptera: Chrysomelidae: Alticinae), potentially noxious to ornamental plants-first record in Poland. - J. Plant Prot. Res. 54: 106-107.

Kumar S., Neven L.G., Zhu H. \& Zhang R. 2015: Assessing the global risk of establishment of Cydia pomonella (Lepidoptera: Tortricidae) using CLIMEX and MaxEnt niche models. - $J$. Econ. Entomol. 108: 1708-1719.

Löbl I. \& Smetana A. 2010: Catalogue of Palaearctic Coleoptera. Vol. 6, Chrysomelidae. Apollo Books, Stenstrup, 294 pp.

Marti O., Braconnot P., Dufresne J.-L., Bellier J., Benshila R., Bony S., Brockmann P., Cadule P., Caubel A. \& Codron F. 2010: Key features of the IPSL ocean atmosphere model and its sensitivity to atmospheric resolution. - Clim. Dynam. 34: $1-26$.

Meinshausen M., Smith S.J., Calvin K., Daniel J.S., Kainuma M., Lamarque J., Matsumoto K., Montzka S., Raper S. \& Riahi K. 2011: The RCP greenhouse gas concentrations and their extensions from 1765 to 2300. — Climatic Change 109: 213-241.

Nekaris K., Arnell A. \& Svensson M. 2015: Selecting a conservation surrogate species for small fragmented habitats using Ecological Niche Modelling. — Animals 5: 27-40.

Orlova-Bienkowskaja M.J. 2013: Dramatic expansion of the range of the invasive ash pest, buprestid beetle Agrilus planipennis Fairmaire, 1888 (Coleoptera, Buprestidae) in European Russia. - Entomol. Rev. 93: 1121-1128.

Orlova-BienkowsKaja M.J. 2017: Main trends of invasion processes in beetles (Coleoptera) of European Russia. - Russ. J. Biol. Inv. 8: 143-157.

Orlova-Bienkowskaja M.J. \& Bieńkowski A.O. 2016: The life cycle of the emerald ash borer Agrilus planipennis in European Russia and comparisons with its life cycles in Asia and North America. - Agr. For. Entomol. 18: 182-188.

Paini D.R., Sheppard A.W., Cook D.C., De Barro P.J., Worner S.P. \& Thomas M.B. 2016: Global threat to agriculture from invasive species. — Proc. Natl. Acad. Sci. USA 113: 7575-7579.

Pelletier T.A. \& Carstens B.C. 2016: Comparing range evolution in two western Plethodon salamanders: glacial refugia, competition, ecological niches, and spatial sorting. - J. Biogeogr. 43: 2237-2249.

Perret D.L., Leslie A.B. \& Sax D.F. 2019: Naturalized distributions show that climatic disequilibrium is structured by niche size in pines (Pinus L.). — Global Ecol. Biogeogr. 28: 429441.

Phillips S.J., Dudík M., Elith J., Graham C.H., Lehmann A., LeAthwick J. \& FerRier S. 2009: Sample selection bias and presence-only distribution models: implications for background and pseudo-absence data. - Ecol. Appl. 19: 181-197.

R Development Core Team 2016: $R$ : A Language and Environment for Statistical Computing. R Foundation for Statistical Computing, Vienna, URL: http://www.R-project.org/.

RADONJIĆ S. \& HRNČIĆ S. 2017: A review of new alien arthropod pests and their impact on agriculture crops in Montenegro. Acta Zool. Bulgar. (Suppl. 9) 2017: 203-210.

Rebelo H. \& Jones G. 2010: Ground validation of presenceonly modelling with rare species: a case study on barbastelles Barbastella barbastellus (Chiroptera: Vespertilionidae). - J. Appl. Ecol. 47: 410-420.

Riahi K., Rao S., Krey V., Cho C., Chirkov V., Fischer G., KinDeRmann G., NaKicenovic N. \& Rafaj P. 2011: RCP 8.5 - A scenario of comparatively high greenhouse gas emissions. Climatic Change 109: 33-57.

Rodríguez-Rey M., Consuegra S., Börger L. \& De Leaniz C.G. 2019: Improving Species Distribution Modelling of freshwater invasive species for management applications. — PloS ONE 14: e0217896, 14 pp.

Salvi D., Bisconti R. \& Canestrelli D. 2016: High phylogeographical complexity within Mediterranean islands: insights from the Corsican fire salamander. - J. Biogeogr. 43: 192-203.

Seebens H., Blackburn T.M., Dyer E.E., Genovesi P., Hulme P.E., Jeschke J.M., PAgad S., PyšeK P., Winter M. \& ArianoutSOU M. 2017: No saturation in the accumulation of alien species worldwide. - Nat. Commun. 8: 14435,9 pp.

Thuiller W., Georges D. \& Engler R. 2016: biomod2: Ensemble Platform for Species Distribution Modeling. R Package Version 3.3-7. URL: http://CRAN.R-project.org/package=biomod2.

Ukrainsky A.S. \& Orlova-BiEnKowskaja M.J. 2014: Expansion of Harmonia axyridis Pallas (Coleoptera: Coccinellidae) to European Russia and adjacent regions. - Biol. Invas. 16: 1003-1008.

Urbani F., D'Alessandro P., Frasca R. \& Biondi M. 2015: Maximum entropy modeling of geographic distributions of the flea beetle species endemic in Italy (Coleoptera: Chrysomelidae: Galerucinae: Alticini). — Zool. Anz. 258: 99-109.

Urbani F., D’Alessandro P. \& Biondi M. 2017: Using Maximum Entropy Modeling (MaxEnt) to predict future trends in the distribution of high altitude endemic insects in response to climate change. - Bull. Insectol. 70: 189-200.

Vincent R. \& Doguet S. 2011: L'altise Luperomorpha xanthodera poursuit son expansion en France (Coleoptera: Chrysomelidae). - Publ. Soc. Linn. Lyon 80: 218-220.

Wang S., Cui J., Li W., Ge S. \& Yang X. 2010: The species of Luperomorpha Weise from China (Coleoptera, Chrysomelidae, Alticinae). - Acta Zootaxon. Sin. 35: 190-201.

Watanabe S., Hajima T., Sudo K., Nagashima T., Takemura T., Okajima H., Nozawa T., Kawase H., Abe M. \& Yokohata T. 2011: MIROC-ESM 2010: Model description and basic results of CMIP5-20c3m experiments. - Geosci. Model Dev. 4: 845-872.

Wieczynski D.J., Boyle B., Buzzard V., Duran S.M., Henderson A.N., Hulshof C.M., Kerkhoff A.J., Mccarthy M.C., MichaLETz S.T. \& Swenson N.G. 2019: Climate shapes and shifts functional biodiversity in forests worldwide. - Proc. Natl. Acad. Sci. USA 116: 587-592.

Wisz M.S., Hijmans R.J., Li J., Peterson A.T., Graham C., Guisan A. \& Group N.P.S.D.W. 2008: Effects of sample size on the 
performance of species distribution models. - Divers. Distrib. 14: 763-773.

Received December 6, 2019; revised and accepted March 18, 2020 Published online March 30, 2020

Table S1. Coordinates of the localities of Luperomorpha xanthodera in both its primary and secondary ranges. Coordinates, in decimal degrees, are in WGS84 datum.

\begin{tabular}{|c|c|c|c|}
\hline Species name & Longitude & Latitude & Distribution \\
\hline L xanthodera & 112.90 & 34.51 & Primary range \\
\hline L_xanthodera & 120.60 & 36.18 & Primary range \\
\hline$L^{-}$xanthodera & 114.70 & 24.47 & Primary range \\
\hline L_xanthodera & 116.00 & 29.70 & Primary range \\
\hline L_xanthodera & 114.20 & 22.56 & Primary range \\
\hline$L_{-}^{-}$xanthodera & 110.70 & 31.75 & Primary range \\
\hline L_xanthodera & 111.00 & 30.83 & Primary range \\
\hline$L^{-}$xanthodera & 110.30 & 31.04 & Primary range \\
\hline L_xanthodera & 110.70 & 31.35 & Primary range \\
\hline L_xanthodera & 119.90 & 28.47 & Primary range \\
\hline$L_{-}^{-}$xanthodera & 120.10 & 30.27 & Primary range \\
\hline L_xanthodera & 121.10 & 28.37 & Primary range \\
\hline$L^{-}$xanthodera & 122.20 & 29.99 & Primary range \\
\hline L_xanthodera & 119.60 & 30.49 & Primary range \\
\hline$L^{-}$xanthodera & 115.00 & 27.09 & Primary range \\
\hline L_xanthodera & 120.70 & 28.00 & Primary range \\
\hline L_xanthodera & 121.20 & 28.41 & Primary range \\
\hline$L_{-}^{-}$xanthodera & 119.10 & 27.62 & Primary range \\
\hline L_xanthodera & 118.10 & 27.33 & Primary range \\
\hline$L^{-}$xanthodera & 118.00 & 27.76 & Primary range \\
\hline L_xanthodera & 119.30 & 26.07 & Primary range \\
\hline L_xanthodera & 117.50 & 27.34 & Primary range \\
\hline$L^{-}$xanthodera & 117.40 & 26.51 & Primary range \\
\hline L_xanthodera & 109.90 & 31.07 & Primary range \\
\hline$L^{-}$xanthodera & 108.80 & 28.84 & Primary range \\
\hline L_xanthodera & 107.80 & 29.32 & Primary range \\
\hline L_xanthodera & 103.60 & 31.48 & Primary range \\
\hline L_xanthodera & 101.50 & 27.42 & Primary range \\
\hline L_xanthodera & 110.30 & 26.39 & Primary range \\
\hline$L^{-}$xanthodera & 110.20 & 29.40 & Primary range \\
\hline L_xanthodera & 112.70 & 25.75 & Primary range \\
\hline$L^{-}$xanthodera & 106.60 & 26.65 & Primary range \\
\hline L_xanthodera & 107.90 & 25.41 & Primary range \\
\hline$L^{-}$xanthodera & 121.20 & 31.10 & Primary range \\
\hline L_xanthodera & 118.80 & 32.06 & Primary range \\
\hline L_xanthodera & 110.50 & 24.78 & Primary range \\
\hline$L^{-}$xanthodera & 110.20 & 25.23 & Primary range \\
\hline L_xanthodera & 116.30 & 31.39 & Primary range \\
\hline$L$ xanthodera & 108.80 & 18.70 & Primary range \\
\hline$L_{-}^{-}$xanthodera & -2.70 & 53.76 & Secondary range \\
\hline L_xanthodera & -2.74 & 53.83 & Secondary range \\
\hline$L^{-}$xanthodera & -2.43 & 53.58 & Secondary range \\
\hline$L_{-}^{-}$xanthodera & -2.16 & 53.34 & Secondary range \\
\hline$L^{-}$xanthodera & -2.06 & 53.40 & Secondary range \\
\hline L_xanthodera & -1.95 & 53.44 & Secondary range \\
\hline L_xanthodera & -1.83 & 53.66 & Secondary range \\
\hline$L^{-}$xanthodera & -1.61 & 53.23 & Secondary range \\
\hline$L_{-}^{-}$xanthodera & -2.13 & 52.69 & Secondary range \\
\hline$L_{-}^{-}$xanthodera & -2.03 & 48.65 & Secondary range \\
\hline L_xanthodera & -2.03 & 48.65 & Secondary range \\
\hline
\end{tabular}

\begin{tabular}{lccl} 
& & & \\
\hline L_xanthodera & 2.34 & 48.86 & Secondary range \\
L_xanthodera & 4.83 & 45.77 & Secondary range \\
L_xanthodera & 4.80 & 45.74 & Secondary range \\
L_xanthodera & 7.75 & 48.58 & Secondary range \\
L_xanthodera & 5.44 & 43.77 & Secondary range \\
L_xanthodera & -1.38 & 46.18 & Secondary range \\
L_xanthodera & 4.81 & 46.27 & Secondary range \\
L_xanthodera & 7.77 & 48.58 & Secondary range \\
L_xanthodera & 10.69 & 43.89 & Secondary range \\
L_xanthodera & 12.35 & 45.39 & Secondary range \\
L_xanthodera & 9.08 & 45.80 & Secondary range \\
L_xanthodera & 7.59 & 47.56 & Secondary range \\
L_xanthodera & 9.73 & 52.39 & Secondary range \\
L_xanthodera & 13.41 & 52.53 & Secondary range \\
L_xanthodera & 6.90 & 51.58 & Secondary range \\
L_xanthodera & 10.53 & 52.28 & Secondary range \\
L_xanthodera & 8.65 & 49.88 & Secondary range \\
L_xanthodera & 9.13 & 48.88 & Secondary range \\
L_xanthodera & 8.69 & 48.89 & Secondary range \\
L_xanthodera & 8.97 & 48.94 & Secondary range \\
L_xanthodera & 9.56 & 51.62 & Secondary range \\
L_xanthodera & 13.39 & 52.51 & Secondary range \\
L_xanthodera & 5.11 & 52.09 & Secondary range \\
L_xanthodera & 5.80 & 53.15 & Secondary range \\
L_xanthodera & 6.38 & 52.52 & Secondary range \\
L_xanthodera & 6.07 & 52.11 & Secondary range \\
L_xanthodera & 5.56 & 52.53 & Secondary range \\
L_xanthodera & 5.94 & 51.24 & Secondary range \\
L_xanthodera & 13.02 & 47.81 & Secondary range \\
L_xanthodera & 21.11 & 52.16 & Secondary range \\
L_xanthodera & 5.32 & 50.32 & Secondary range \\
L_xanthodera & 3.06 & 42.34 & Secondary range \\
L_xanthodera & 39.92 & 43.43 & Secondary range \\
L_xanthodera & 39.75 & 43.58 & Secondary range \\
L_xanthodera & 39.94 & 43.41 & Secondary range \\
\hline & & & \\
& & & \\
\hline
\end{tabular}

Table S2. The coded set of nineteen candidate predictors and corresponding explanations (from Worldclim.org). Variables in bold are the ones used for modelling.

\section{BIO1 = Annual Mean Temperature}

$\mathrm{BIO} 2$ = Mean Diurnal Range [Mean of monthly (max temp - min temp)] $\mathrm{BIO} 3=$ Isothermality $(\mathrm{BIO} 2 / \mathrm{BIO} 7)^{*} 100$

BIO4 = Temperature Seasonality (standard deviation*100)

BIO5 = Max Temperature in Warmest Month

$\mathrm{BIO6}=$ Min Temperature in Coldest Month

$\mathrm{BIO} 7=$ Temperature Annual Range (BIO5-BIO6)

$\mathrm{BIO8}=$ Mean Temperature in Wettest Quarter

$\mathrm{BIO9}=$ Mean Temperature in Driest Quarter

BIO10 = Mean Temperature in Warmest Quarter

BIO11 = Mean Temperature in Coldest Quarter

BIO12 = Annual Precipitation

BIO13 = Precipitation in Wettest Month

BIO14 = Precipitation in Driest Month

BIO15 = Precipitation Seasonality (Coefficient of Variation)

BIO16 $=$ Precipitation in Wettest Quarter

$\mathrm{BIO17}=$ Precipitation in Driest Quarter

BIO18 = Precipitation in Warmest Quarter

$\mathrm{BIO19}=$ Precipitation in Coldest Quarter
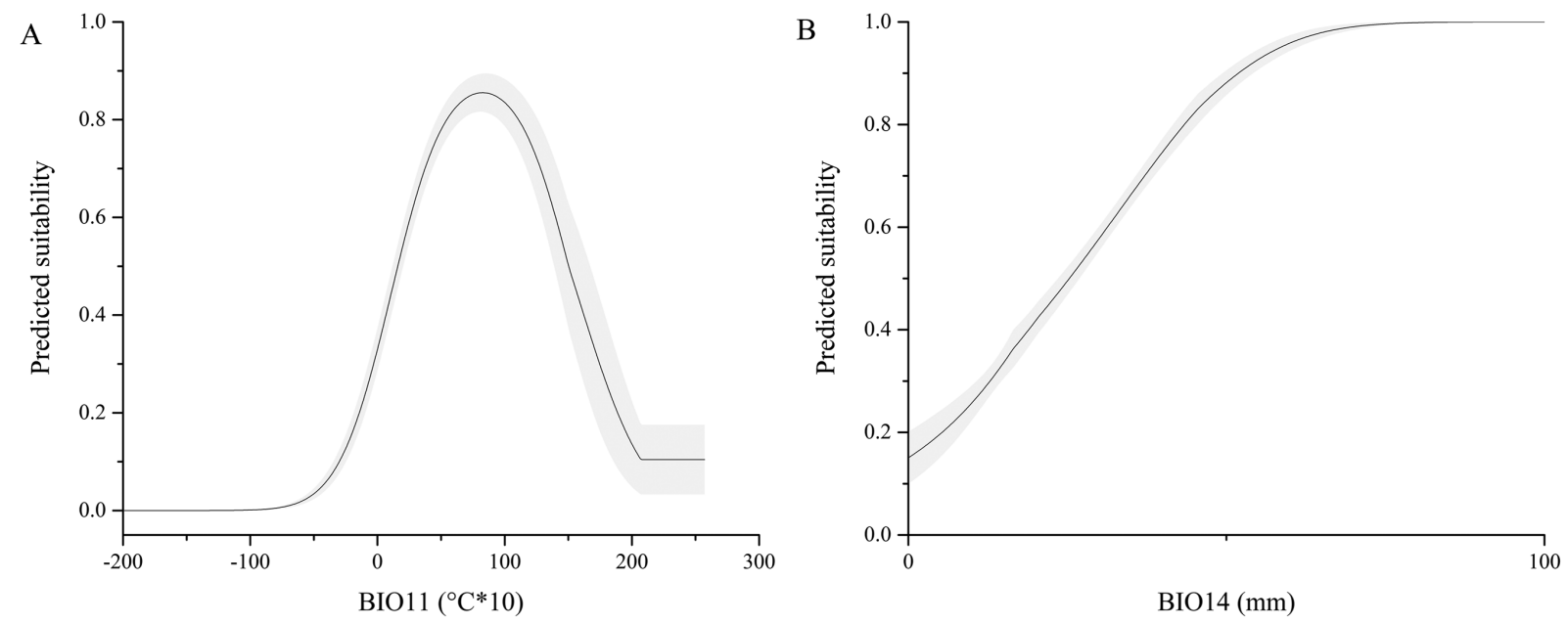

Fig. S3. Marginal response curves recorded for Luperomorpha xanthodera in response to the two highest contributing predictors (grey standard deviation). A - BIO11, Mean Temperature in Coldest Quarter; B - BIO14, Precipitation in Driest Month. 